\section{ADDRESS IN PATHOLOGY.} CHARLES CREIGHTON, M.D.

\section{ON THE AUTONONOUS LIFE OF THE SPECIFIC INFECTIONS.}

Mr. President and Gentlemen, - I have unusually good reasons for prefacing my address with an apology. I cannot claim to speak from the fulness of experience, which has given so much value and distinction to the addresses that have been delivered before the Association; and I have a subject assigned to me which demands experience and a mature judgment in no ordinary degree. Pathology is a growing science, its aspects are constantly changing, a single year's work brings us a multitude of new and often puzzling facts; and although the issues are of the most momentous kind, not even the wisest and most judicial minds in the profession can alway see their way to a clear and definite opinion.

But, amidst all this uncertainty, there is one central and guiding prinoiple in the doctrine of disease which we may hold fast to. It is the physiological principle, or the idea that diseased states of the body are but modifications of healthy states, deviations from the beaten track, perturbations of the normal life, shortcomings of the physiological standard. Thus, even in so formidable a malady as diabetes, we are still within sight of the line of health; there may be a physiological glycosuria; and that fact, as Dr. Bence Jones says, proves to as that the disease is only a little way. distant from health. "Here as elsewhere," says that eminent chemist and pathologist, "there is no definite limit where health ends and disease begins." To find the proper physiological analogies for diseased processes is the task of modern pathology; and I do not think that there is, in the whole range of science, any better kind of intellectrial exercise than to expose the working of the ordinary laws of structure and function under the mask of disease. The physiological idea is, indeed, the hope and inspiration of pathological science, as it is also of medical practice. But there is no reason why I should attempt to say again what has so often been well said before. Members of the Association who heard Professor Michael Foster, at the Cambridge meeting; disconrse on the "Relations of Physiology to Pathology," will not have forgotten how he proved that the difference between these two sciences was merely a superficial difference, whether as regarded method or subjectmatter. We shall, most of us, also recall Professor Huxley's lucid exposition before the International Medical Congress, of the "Connection of the Biological Sciences with Medicine," wherein he showed that pathology was that branch of biology which concerned itself with perturbations of the normal life.

That view of pathology is one that we all share; and as I have endeavoured, according to my opportunities, to work out physiological analogies of disease in particular instances, I shall not be suspected of any want of sympathy with the general principle. But I am none the less confronted with the difficulty that a great deal of pathology appears to be quite different in kind from any physiology known to us. What are the physiological analogies of the infective and constitutional diseases, and how large a part of pathology do the diseases of that class stand for ?

There is, I believe, a serious difficulty here, and"a difficulty that made itself felt in the very first system of physiological medicine that was given to the world. Broussais was the author of the first attempt at a physiological scheme of disease; and it was only a year or two ago that Professor Charcot was claiming for his brilliant countryman the credit of having broken down the dualism of health and disease, and of having eradicated that old and permicious habit of regarding disease as a separate entity. But Professor Charcot said nothing of the rock on which Broussais is generally accounted to have made shipwreçk. The author of the first physiological medicine was thorough-going, and it was because he endeavoured to be comprehensive and consistent that he failed. He left out no great disease from his physiological scheme, not even typhtis nor Asiatic cholera; they were all perturbations of the normal life, and a good many of them were forms of gastro-enteritis. Professor Charcotimay be right in claiming the physiological medicine of Bronssais as the exmple for all subsequent times; but it is quite certain that it served also as a warning to those who next took the physiological medicine in hand. They were carefal to lighten the ship by throwing overboard Asiatic cholera, typhus fever, and, in fact, the whole of the acute and chronic infections. Just about the time when the thorough-going system of Broussais had provoked the inevitable reaction, Professor Henle had made his suggestion about minute parasitic organisms being the causes of the specific infective diseases; and it is curions to read, at a distance of forty years, in the first volume of the German Archives of Physiologioal Medicine (p. 88), how Griesinger, one of its sponsors, promptly availed -himself of the parasitic hypothesis of Henle in order to account for all those diseases which had been prudently omitted from the physiological programme.

But I venture to say that, when we congratulate ourselves upon the physiological basis of pathology, we do not always reflect how much of disease is thus excluded from the class of disturbed physiological processes, and how small a fraction remains to fill the physiological categories. There are several passages in Sydenham's works in which he gives his estimate of the proportion that the species of disease-the morbi typo induti-bear to the rest ; he estimates diseases of a specific type at two-thirds of the whole; and it will be admitted, I think, when we look abroad as well as at home, and when we read history as well as contemporary records, that this estimate shows his fairness of mind and his sense of proportion.

The serious difficulty, then, which I spoke of-the difficulty that must have been present to the mind of Broussais, and must occur more or less to everyone-is that a physiological medicine, which leaves out the larger and more formidable half of disease, is hardly worthy of the name. The dootrine that morbid processes are after all merely perturbations of normal processes, or, as Hunter said, "a perversion of the natural actions of the animal economy," is the great principle of scientific pathology; but we shall have to speak less enthusiastically of it, if it should appear that it has no place for the long list of infective diseases-for plague, for cholera, for yellow fever, for typhus, for small-pox, for leprosy, for syphilis, for cancer, for consumption. If the physiological idea is to be good for anything, it ought to be good for those; for they are the real difficulties of pathological science, and the real opprobria of the medical art.

I am sanguine enough to believe that the physiological doctrine will one day be shown to be as large in its application as it is rational and hopeful in its spirit. It is for that reason that I have decided to use this public opportunity that has come to me-and $\operatorname{come}$ to me most unexpectedly, and, I feel, most undeservedly-in order to speak of certain aspects of the specific infections, which are perhaps not the aspects most commonly brought before us at present. One would wish to think of these diseases, strange and terrible though they be, as still joined in continuity with the common disorders of structure and function; and I am accustomed to express for myself this connection by a formula, which has no other value than belongs to a mode of thought or a form of words, but may still serve as a convenient or empirical standing ground for those who seek to observe a certain unity and sequence in their study of disease.

I shall endeavour, then, to discover some relation between common aberrations of structure and function and the specific infections, or a relation between disordered states of the body and the self-existent species of disease; and I shall make this attempt with two or three representative instances. It will be convenient to begin with cancer, for the reason that the suggestions that I have to make arise most naturally out of the study of cancer.

Cancer is an infection, although its infective power does not extend, except in heredity, beyond the individual body in which the disease takes its rise. I do not forget that some pathologists consider cancer to be no more than an overgrowth of epithelium. But we shall find it difficult to explain to a patient with cancer that he is suffering merely from an overgrowth of his epithelium. All the world knows what cancer is, and no microscopic analysis will ever persuade men that cancer is anything but the devouring thing, the implacable enemy, that the common eye sees it to be. What the microscope does show us, is that a cancerous tumour has not always been cancerous. If we take any of the common seats of cancer-the stomach, or the uterus, or the breast,-we shall find that the disease may be traced back to a point at which it comes within the category of structural and functional irregularities. I say structural and functional, because it seems to me that if we attend only to the structural features of the disorder, as some of our German colleagues are content to do, we are likely to miss the central idea of the deviation from the normal. In the favourite seats of cancer, the secretory function is not always or altogether 
What we often take sectetion to bo: Under oertain circumstances, colid produots, or cells; form part iof the secretion, and those cells 'do not always get carried off; as' the cells do in an ordinary catarrh, -by discharge from the surface; or by way of the lymphatic drainage, but they may stagnate and acotumulate in the deeper textrares of the organ or part. So far, there nothing', in the morbid process for which we may not find close; physiological analogies. In some of the secretions of the invertebrata, and even in certain glands of the 'higher animals, the secretion' tetaims' its soliat or cellular character for a considerable time.: Again, the heaping up of the solid or byeproducts of secretion in the spaces of the underlying connective tissue is found to oecur in the broast as a perfectly natural incident.

Still further, the free space of a gland maty become filled with -cast-off epithelial cells; or the 'opithelial lining may bo raised into wart-like growths: Even a whole gland, like the breast; or a whole lobe of the gland, may be uniformly affected in the way of overgrowth, producing an adenomatous condition, or the condition of simple glandular tamour. There is nathing cancerous in all this ; we are still within sight of the line of hesilth. The cancerous element comes in usually after a partioular time of life, and it consists in the implication of other tissues than the glandular or secreting structure, whose irregularities twere the exciting cause Epithelial cells that have not been used for secretion can become mischievous as infecting cells, and if we now examine the region of disease, we shall find the-marvellous spectacle of an epithelial kind of stracture springing from the tissues around where there is no epithelium naturally; a little later, the same epithelial pattern is as it were, carved out of the parendhyma of lymphatic glands, or of the liver, or in the deeper layers of the skin, or even in still more 'unexpected places. The pattern of this widely distributed structure is always the :same in a given case, and there is always something in it which reminds us of the primary : seat of glandular disturbance: An intelligible disorder of structure and function, not without its close analogies in physiology, has acquired a kind of individuality ox independence, and $a$ power to reproduce itself throughout the body; - or, in other.words; it has become a ravaging cencer.

I shall not delay hore to go into the partioulars of this extraordinary process; or to enter upon controversial matters. $\therefore$ I take ancer as a striking instance of a disease which thay be traced along the track of physiological perturbations for a certain distance, after which it becomes what all the world knows it to be-a semi-independent life, an imporiune in imperie, a power inseparable from the general life of the body, compatible even with blooming health for a time, but in the end sure to gain the mastery.

In taking a full and fair view of cancer, of its physiological beginnings, and its ultra-physiological oourse, we cannot but admit that there is some trath in'that hard saying of Paracelsus: "In stich $\theta$ disease, a man is himself and another, he has two bodies at one time, enclosed the one in the other, and yet he is one man." This kind of Platonio mysticism is not what one would choose to import intoesact science. Bat we are bound by a regard for facts; and I do not sea hot the facts of cancer, whether they be microscopic or clinical,can be done justice to, anless we admit that a state of the body may be raised to the power and dignity of: a life of semi-independence. .. I purpose speaking, in the sequel, of this semi-independence under the name of autonomy ; and I shall endeavour to show, in the case of two or three other representative infective diseases, how a perturbation of the physiological life has acouired its autenoray, or what the preautonomous stage of those infections may have been. This doctrine of a a quired antonomy and the preatutonomous stage is the formula in terms of which $I$ would express the relation between : ordinary perturbations of' structure and function and the speciflc infections, the relation between disordered states of the body and the selfexistent species of disease.

If cancer has always been the great popular instance of a disease enjoying a kind of life of its own within the body, consumption hardly yields to it in its relentlessness, and it far exceeds it. in it prevalence. Is it possible, in the case of consumption, to show that a wasting infection has arisen out of common disturbances of the physiological life? Before so critical an audience, I shall not have the hardihood to speak of consumption in general-of the disease about whieh so great masters in pathology as Iaennec and Virchow have differed widely. But there is a form of tubercle, the bovine form in which the facts are much less ambignous; and much easier to deai with, and; as it- happens, more familiar te myself; and for botine tubercle, or, as it is sometimes called, the pearl-disease, I shall venture to inquire whether the small beginnings of it may not be found in a certain kind of disturbarce of ruminant nutrition, just as we find the pre-cancerous stage of cancer in certain irregularities of the apparatus : and process of secretion. Those beginnings would coriespond to what I have called the pre-autonomous stage; while the :artonomons life of the disease, as a semi-independent thing, would be shown in its infectiveness.

Bovine tubercle is a more complete example of infection than cancer. It is a constitutional disease pervading the whole body; it is likely to end in wasting and cachexia; it is very liable to be inherited by the offspring; it can be given to other animals, by inoculation or by feeding, in experiments, and probably also by accident; and there are recorded cases in veterinary practice, which lead us to think that it hangs about a stall, or spreads from stall to stall by volatile. contagion. There is, in fact, no disease, in human or veterinary pathology, that shows a more complete autonomy; it is constitutional, hereditary, infective, and contagious.

The pearl-disease is peculiarly a ruminant malady, and it is curiousty limited within the ruminant order itself. It does not occur in the sheep, nor, as far as we know, in the deer; and by far the larger number of cases are found in the domesticated bovine species, in whinch it is, indeed, much too common. I have been on the outlook for specimens of it among the animals that die in the Zoological Gardens. in London, and my experience hitherto has been curious and suggestive. I have hitherto found the peculiar anatomical characters of this form of tubercle in only three species : the eland, a large South African antelope, like a cow; the nilghau, a large Indian antelope, whose name means " the blue cow ;" and the pronghorned antelope from America, another of those half-way animals between the bovines banid the antelopes, which the late Mr. Forbes, the prosector at the Zoological Gardens, took much interest in as a transition species. It is certainly a remarkable thing that those antelopes, which resemble the bovines so closely in zoological characters, should resemble them also in their liability, under confinement; to a distinctive kind of new formation. This kind of tubercle is not onlyan affair of the ruminant order, but it is an affair of a small group of ruminants, mostly belonging to one genus.

What, then, are the distinctive anatomical characters of this distinctively ruminant disease? The morbid anatomy of bovine tuberculosis has been written with as little reference to theory or preconceived opinion as could be wished. It has been, in great part, observed by those whose business lies with cattle; and the popular names of the disease in all conntries will show us how it has presented itself to the common observer. The various names show that it is primarily an affection of the serous membranes; the Germans have called it the "pearl-disease," from the rounded whitish nodules attached to the abdominal and thoracic surfaces; the French have named it "pommeliere," from a fancied resemblance of the nodules to clusters of potatoes; in England, it has been called " the grapes;" and, in -Scotland, "angle-berries." I am. merely repeating the language of all authorities, inoluding Professor Virchow, when I say that the disease is primarily one of the serous membranes-a growth of multiple nodules, :usually small and flattened, often suspended by a stalk; and sometimes as large as a cherry or an apple. These are the beginnings of the disease; but it extends from the serous membranes, by infection, to the lymphatic glands, which become changed into the same mortar-like substance that is found in the degenerated nodules. - The lungs, also, are very apt to get infected, as they so often do. with new formations of a sarcomatous nature; and the infection may, in the end, reach most of the argans, as well as the bones and joints, causing the animal to die of general cachexia and wasting.

Such is the usual sequence of events where the disease is originally qaquired; but in the eases of inheritance-and these are now estimated at more than one-half-there may be some departure from this order:-in them, the formations in the lymphatic glands, lungs, and other viscera, may.be more conspicuous than the serous-mem brane nodules; but even in the inherited disease, the pleural or peritoneal surfaces, will usually show characteristic traces of the primary new formation. Some allowance must be made for certain primary in the order and distribution of the disease, when it is communiested direetly to the offspring by a sire or dam which had acquired it; and it is all the more necessary to be clear on this point, since, at the present day, the hereditary taint would seem to -be so widely distributed throughout the bovine stock as to obscure somewhat the original characters of the disease. In what I have to say, I mast speak of the disease as it is primarily acquired, and as it is described in the earliest writings, and by its popular names.

It starts then, as a multiple nodular condition of the abdominal 
and thoracic serous surfaces, it acquires the character of a constitutional disease, it goes all through the body, it passes directly to the offspring, it may be inoculated upon healthy animals or communicated to them by feeding, and it is not improbable that it passes by volatile contagion. The infectiveness within the original body, and the faculty of passing to other animals, is what I would call its autonomous life, and I would look for its pre-autonomous stage in the peculiar groups of multiple nodules on the serous surfaces. What then is the origin of these nodules, in what relation do they stand to any known disorders of ruminant nutrition, or rather, of the nutrition of those ruminants that are closely confined, artificially fed, and over-milked?

I am not aware that the suggestion which I have to make has occurred to anyone before, and I put it forward, therefore, with some diffidence. This suggestion arises out of a consideration of the forms and favourite seats of the nodules, and of their structure, and degenerations. One cannot help observing that these multiple nodules are especially apt to grow in the seats of fat-formation, and to assume the external form of deposits of fat, either the stalked and pendulous form, or the flattened form of confluent lobules or patches. Now the bovines are somewhat peculiar in the way in which they lay on fat. They have not so much of subcutaneous fat as the sheep or the pig, but they are very apt to have internal formations of adipose tissue, sometimes in situations. where one would imagine that it could serve none of the ordinary purposes of fat. Besides the common deposits of fat about the abdominal organs and in the thorax, there may be lumpy masses of it even on the pleura covering the ribs, and on the diaphragm; and, in highly fed animals it is not unusual to find a lobulated layer of the same tissue all over the surface of the spleen, and even on the surface of the liver. It can hardly escape us that those serous surfaces which are invaded in the course of this excessive fat-forming habit, are just the localities where the pearl nodules are found. There is, indeed, one rather important exception to this rule, namely, the borders and surfaces of the lungs. I cannot say whether a border of fat ever occurs round the margins of the lungs in cattle, as it occurs round the spleen and liver, or under the pulmonary pleura, as it is found under the costal pleura; but, if that should be the case, the analogy with the pearl-disease would be complete, so far as situation goes; otherwise, we must explain the nodule of the pulmonary pleura on the hypothesis of secondary infection. As regards form, the resemblance between the physiological and the pathological formations is most striking; in both cases we may find either a finely lobulated stratum of translucent tissue, or coarser lumpy masses, or pendulous nodules.

But, after all, the diseased nodules of the serous membranes are not fat, or, at all events, they are not composed of adipose tissue throughout most of their extent. They are not multiple lipomata but it would be strictly correct to describe them as multiple fibromata or sarcomata with a deficient blood-supply, or rather as a multiple tumour-formation containing a mixture of those two kinds of tissue, growing in the seats of fat-formation, and assuming the lobulated, or lumpy, or pendulous forms of the sub-serous fat.

I do not think that I have gone beyond the facts in this statement of the naked-eye characters of the primary new growths to which the bovines are so liable, and I cannot help thinking that there must be some connection between them and vicissitudes in the nutrition of those animals as manifested in that tissue which would be most affected in nutrition, namely, the fat-tissue. The facts may be explained in two ways, both of which may be applicable, although I would regard one of them as more probable than the other. Fither the formations on the serous membranes are atrophied or degenerate masses of fat in which the blood-supply has failed to a great extent, or they are radically new growths which have sprung up in the old lines of fat-formation or where fat may once have been. The description in a veterinary text-book of retrogressive changes in the multiple lipomata of the serous membranes, reads very much like a description of some of the bovine tubercles that we meet with ; the oily contents of the fat-cells disappear, the connective tissue hardens and thickens, calcareous matter is deposited, and a mortar. like substance takes the place of what once was fat. But there is another and perhaps better way of accounting for the fact that the morbid growths are found in some of the favourite seats of the internal fat and in its peculiar shapes. It is a well-known zoological characteristic of the bovines that their fat is naturally apt to come and go from time to time, in the wild state, according to the periodicity of the seasons, and in the doinesticated state, according to a multitude of artificial practices in the management of dairy and farm stock. Nothing can be more artificial; for example; than the condi- tions which cows in town dairies are subjected to: the close confinement, the unnatural feeding, and the excessive milking. It is quite conceivable that an animal, under those circumstances, and more especially when it is growing old, would depart from its natural fatforming habit, and put on, instead, an embryonic kind of tissue, which is neither fat nor anything else of a physiological kind, although it occupies the old seats of adipose tissue, runs into the familiar mould, as it were, and grows to the old pattern.

Whether we take the one explanation or the other, or the two together, there is, I think, a pretty strong chain of evidence that bovine tubercle begins as a disorder of nutrition. It is oftenest acquired by animals that are farthest removed from their natural conditions--by cows imprisoned in town dairies; and the disease that those animals are so peculiarly liable to begins as a kind of multiple morbid growth, which occupies the very seats of the internal fat and runs into its very shapes. Now, the abdominal and thoracic fat is precisely the tissue that might be expected to show the effects of malnutrition in the way of structural changes. The tubercles are simply collections of embryonic tissue in which the formation of blood-vessels has been inadequate, and in which degeneration has inevitably followed; and anyone who has studied the development of fat will readily admit that the same embryonic cells growing in the particular localities might have become fat-cells if the blood-supply had been sufficient.

Whether I have indicated truly or not the circumstances in which we should seek for the beginnings of this peculiar kind of new growth, I am confident, at least, that we must look for these beginnings in some physiological disorder or other within the small group of ruminants, and not elsewhere. Disordered nutrition appears to me to be able to account for this kind of multiple tumour-disease, just as I believe that disordered secretion can account for the beginnings of cancer. Disordered nutrition shows itself in various ways within the body; but there is only one tissue that it specially affects, and that is the adipose tissue, just as the glandular tissue is the proper seat of secretory disturbances. In the one case as in the other, the disorder of function finds a structural expression; it acquires length, breadth, and thickness; or, in other words, it results in a tumour. The functional disease thus acquires the degree of individuality which may be ascribed to a tumour, and that must be the beginning of its life of semi-independence within the body. In both cases, the pre-autonomous stage is a common disorder of structure and function-of secretion in the one case, and of nutrition in the other; and each goes on to acquire the mysterious power of infection. But they become auton. omous in different ways, or under different circumstances. I have already spoken briefly of cancerous infectiveness, and I have elsewhere endeavoured to trace the connection between it and the antecedent glandular disturbances. In bovine tubercle, I should ascribe the infectiveness to the multiplicity of the primary nodules, and to the fact of their being seated on the serous membranes, which are so fundamental a part of the lymphatic system. Multiple tumours of the serous membranes are favourably situated for infecting the lymphatic glands, and the infection of the lymphatic glands is only the beginning of an autonomous career. Professor Virchow has shown in his great work on morbid growths, how the lobules of abdominal fat may become multiple stalked lipomata, each lobule becoming a kind of individual tumour, and growing as such; and he adds the following remarkable words: "There is no doubt that this kind of multiplicity does not differ altogether from what we find in malignant tumours or in an infective dyscrasia ;" and if that can be said of multiple lipomata still retaining the proper structure and nutrition of fat, it can be said, with even greater truth, of those multiple growths of the abdominal and thoracic surfaces which we have good reason for taking to be rather the degenerations or substitutes of the fat.

There is one other point to be noted in connection with bovine tubercle. It may or may not be primarily due, as I have supposed, to an error of nutrition in the abdominal and thoracic deposits of fat, but its morphological characters are certainly peculiar, and theJ belong, in a sense, to the bovine organisation. If I may so speak, it has sprung out of bovine soil, and the marks of its bovine origin never quite leave it, even when it is set up in the bodies of animals widely removed from the ruminants. A mere condition or state of the ruminant body can be abstracted, as it were, from all other ruminant conditions, and made to live in another body; and that is an extreme instance of what is meant by the autonomous life of the specific infections, or of the semi-independent existence of the species of disease.

Having presented cancer, and one of the varieties of tubercle, in 
this light, I shall next inquire whether this formula of an acquired autonomy may not be applied to a third great disease, representative of another class of infections, I mean small-pox. Small-pox may be looked at from more than one point of view without losing sight of its main features. Our great English dermatologist, Willan, looked upon small-pox as a skin-disease; but Willan was also one of the first to investigate the history of small-pox epidemics throughout the world, and he was not likely, therefore, to underrate its importance as a pestilence. Hebra also ranks small-pox among the cutaneous disorders, and the anthorities of the Allgemeine Krankenhaus at Vienna have given practical effect to Hebra's. doctrine so far as to place the smallpox wards ander the department for diseases of the skin; and I can testify, from an experience of the Vienna small-pox wards, that the disease does not lose any of its contagious power by being classified among skin-diseases. An experience gained under those circumstances is apt to make an impression, and, from that time, I have never been quite able to think of smallpox except as an ill-smelling condition of the human skin which one person may impart to another. It is a skin-disease which has been reproduced with the greatest accuracy and fidelity in millions of copies for hundreds of years, and the extraordinary closeness of the mimicry has given rise to the opinion that the disease is really the uniform effect of some unknown poison. But the anatomical structure and evolution of the pock is too elaborate to be the simple and direct effect of an extrinsic poison; it is not like a flea-bite, or like the nettle-rash which comes out in some peculiarly constituted persons after eating shell-fish, or, as I have known, even from eating a single wholesome strawberry. The pock is a complicated affair, and there is a history written in it, a history of characters acquired bit by bit, as in the evolntion of living things, a history which has been transacted within the body; and the stages of this history are run through with more or less completeness in every case of the communicated disease. The papules had developed fluid in their summits, they had grown in a peculiar way to the breadth, the original centre had become a distinct depression and in the course of this evolution, certain partitions had been formed in the interior of the pock. Farther, the pock is more deeply rooted in the skin than most skin-diseases known to us ; for its base goes down to the vascular layer of the corium, and, when it scabs, it leaves a considerable defect of substance, (more particularly in those localities such as the face, where the vascular layer of the corium is well developed,) a peculiarity among skin-diseases which can hardly be matched unless it be in some of the tropical forms of impetigo. This skin-disease is ushered in by much con stitutional disturbance or fever; and, as in some other skin-diseases which are not contagious, the fever abates when the eruption has come out, and the subsequent constitutional disturbance is exactly in proportion to the number of the pocks.

The remarkable thing is that all this complexity of anatomical structure, of stages of evolution, and of characteristic fever, should have preserved its unity and individuality through so many transmissions, in all sorts and conditions of men, and in all parts of the world. The disease possesses what I would call autonomy in a high degree, and, from that point of view, it becomes a matter of no ordinary interest to inquire into its pre-autonomous history.

Professor Hirsch, in his Handbook of Geographical and Historical Pathology (a work which we are soon to have in an English dress), concludes an elaborate review of the historical evidence about smallpox with the opinion that we have to go to tropical countries, to Hindostan and to the interior of Africa, for its original seats, and to go back to a remote antiquity to find the beginnings of it. Lichtenstein, one of the early explorers of Africa from the southern end, found small-pox to be prevalent wherever he penetrated, and he found it among tribes who professed to have got it from nations still farther from the sea. According to Pruner, the disease is peculiarly an African disease. We may take it, therefore, that small-pox was originally a disease of the black skin, and it is in keeping with that historical and geographical induction to find that the black-skinned races are by far the most susceptible of the disease even nowadays, when it is set up only by contagion.

It is impossible to speculate to any purpose on the rise and development of small-pox out of some common and frequent disorder of the black skin under such influences as tropical heat and moisture or under the peculiar conditions which obtain among the swarming populations of tropical countries. One naturally thinks of a complex form of "febrile lichen," a skin-disease which Dr. George Gregory admits that he could not always diagnose from smallpox; and if we imagine a widely prevalent kind of febrile lichen to follow somewhat the same development that Willan describes in a remarkable case of lichen agrins, we should have a not very remote analogy for what I should call the pre-autonomous stage of smallpox, both in the structural characters and in the cons'itutional fever. We are, at least, justified in thinking of some form of tropical skindisease, widely spread within a certain zone, very apt to recur in the individual, and with each recurrence to become more inveterate, and to develop a more complex structure. Given a number of people suffering from such a cutaneous disorder at one time, and some great migration or invasion, and we shall probably have the circumstances under which the skin-disease would become communicable, would pass by contagion to the skins of those who had never incurred the disease by natural causes, and pass all the more easily to them if they belonged to an entirely different race, or presented the ordinary contrasts of civilisation and barbarism, of white skin and black.

I do not say that it is an easy thing to construct the circumstances under which this disease of the black skin acquired, what I would call, its autonomy. It was probably a gradual process; its semi-independence must have been hardly won and slowly consolidated, until, at length, it was ready to start on its devastating campaigns. Small-pox has been a disease on so stupendous a scale, that it must seem to be mere hardihood to speak of it as a condition of the skin, originally acquired in the tropics, which has been passed on from one body to another. But, even if history and geographical distribution had told us nothing, the loathsomeness, the peculiar odour, and the no less peculiar scars of small-pox, might of themselves suggest another skin than ours; and I have seen too many instances of the minute mimicry that goes with every infection, to feel any surprise that a disease, which is native under a tropical sun, should impress upon its victims in every country something even of the primary ethnological characters.

And now let us compare the autonomous disease, as we know it, with the original skin-disease out of which it must have grown. The contagious small-pox is distinguished by what Sir Thomas Watson calls "the very curious fact" that it generally occurs but once in a person's life. "In this," says Watson, " the contagious disease offers a remarkable contrast to inflammations, which, having happened once, are, for that very reason, more apt to happen again ;" and he goes on to show the impropriety of ranking smallpox under the head of cutaneous diseases; it would "more rightly be called a blood-disease." Bat there need be no antagonism between the view of small-pox as a cutaneous disease, and the view of it as an infection. This formula of an acquired autonomy, and of a pre-antonomous stage, which $I$ have been recommending as a sort of nostram for our intellectual difficulties, appears to me to be a means of reconciling those antagonistic opinions which have arisen, not so much in connexion with small-pox, as in the controversies about some other infective diseases, which are supposed still to develop de novo from time to time. Small-pox, in its pre-autonomous stage, would be precisely that kind of skin-disease which, having happened once, is, for that very reason, more apt to happen again; it would recur in the same spots, as in the early stages of leprosy, and it won!d become more rooted and more inveterate each time it came beck. The inveteracy of this morbid condition of the skin, due in part to neglect, would be its first step towards acquiring that remarkable power of semi-independence within the body, which I have been endeavouring to illustrate under the name of autonomy; it is this acquired power that enables it to pass to another person's it is the body, which can be, as it were, abstracted ; and its individuality is proved by the best of all tests of what constitutes an individual-the test of parentage; for the skin-disease that springs up in the contaminated body is exactly like the skin-disease which must have been originally acquired. But the infected or impregnated body runs through all the stages of the malady-papule, vesicle, pustule, scabbing, and scarring-in rapid succession in two or three weeks, and it is thenceforward done with that particula form of skin-disease for ever. This antonwith that par the disease is a brief abstraet and chronicle of its whole protracted development or evolution; it sums up the past, and just as it sums up the past, so it anticipates the future.

small-pox appears, then, to be a clear case of a morbid condition of the body, namely, a cutaneous condition, which has been enabled to lead a kind of independent life. But small-pox is one of those diseases that always pass directly from one body to another, and the eases that always pass direct snccession of cases does not appear ever to have been broken. There is, however, another large class of infections, corresponding to Pettenkofer's division of the exogenous contagia, which are not only able to subsist for long periods outside the human body, but 
which even require a certain amount of external putrefaction in order to make them potent. Cholera is one great example of a disease of the exogenous group, and yellow fever is another; and I shall ask your attention for a few minutes to some facts relating to the latter disease ; for here, at least, it must seem as if we had got quite away from common disorders of structure or function, and into an absolutely separate region of disease, where the physiological principle daes not serve us.

Yellow fever is one of those maladies in which historical and geographical facts are of even greater importance than microscopic or chemical, and hardly less important than clinical; and, as I have been lately occupied in turning into English the German sentences of Professor Hirsch's treatise on Geographical and Historical Patho$\log y$, I have had occasion to reflect upon the more salient facts in the history and geography of yellow fever. The first point that strikes one is, that it appeared in the seventeenth century as a new disease. For more than a century after the Spanish conquest of $\Lambda$ merica, and for many years after the first English and French colonisation in the west, there was no yellow fever, and, when it did come to Guadaloupe and Barbadoes, it was recognised as something quite different from the ever-present malarial fever. The next point is, that there is something quite peculiar in its geographical distribution. At the present day, we are apt to think of yellow fever as the fever of the Gulf of Mexico and Brazil; but it had been the scourge of Philadelphia, and even of New England, for many years before it broke out in New Orleans at all (1796); and its first appearance at Rio was in 1849. In reading Bancroft's treatise on this disease, published in 1811 , it is curious to notice how much yellow fever has shifted its ground; it has always remained true to certain shipping places in the West Indies, but the other great centres in Bancroft's time have absolutely ceased to be the seats of yellow fever; and some of the places that are among the worst seats of the fever now are not even mentioned in Bancroft's pages. In fact, it is not latitude and longitude that explains the peculiar distribution of the disease. There is only one thing that covers its history, and its geography and the remarkable changes in its distribution, and that is the slave-trade. Disregarding its occasional and widely ranging excursions, and confining the attention to the localities where it is or has been, at one time or another, endemic or repeatedly epidemic, these are found to be the creeks and wharves and low shipping quarters of the ports of debarcation of the slave-trade, together with a few much less endemic, but not less significant spots, in Spain and on the west coast of Africa-the places to which vessels engaged in the contraband slave-trade had gone on their return voyige. The single exception to this curious rule is Peru; but Peru is hardly an exception, when we bear in mind the many points of resemblance between its coolie trade across the Pacific and the old African slave-trade.

It was an inquiry into the disastrous outbreak at Barcelona in 1821 , in which 5,000 persons died, that gave the first clue to the connection between yellow fever and the slave-trade. The circumstances were investigated by Dr. Audouard for the French Government, and the same physician was sent again in 1823 to inquire into a more limited epidemic at a small port in Biscay. The facts were very much the same in the two outbreaks; ship-carpenters, engaged in repairing vessels that had arrived some time before from the West Indies, were seized with a prostrating illness, which they attributed to putrid emanations from the bilge water, and they became the first victims of an epidemic which proved to be yellow fever. Dr. Audouard found that the vessel which started the infection in the 1823 epidemic was a slaver; and, on recalling the facts of the Barcelona outbreak two years before, he found that the two vessels chiefly concerned in it were also slavers, in proof of which, he said they might still be seen with the irons for securing the slaves fixed in the planking of their holds. It was ascertained also that one of them had had an extraordinary amount of dysenteric sickness and mortality among her human cargo on the previous voyage. He caleulated that about sixty Spanish vessels had been engaged in this contraband trade in 1820 , that they had taken out about 15,000 siaves from Africa to the West Indies, and had returned to Spain with merchandise before going down to the African coast for their next cargoes. This was, in fact, the time of the irregular slavetrade, when the vessels were not adapted for it, and the crowding and sickness on board was at its worst; and this period corresponds to the remarkable outburst of yellow fever, both in America and in Spain and on the West Coast of Africa, from about 1790 to 1820

It is a perfectly well-known fact, admitted equally by Lind and Bancroft, that the slaves on board a slave-ship did not suffer from yellow fever, although they suffered much from dysentery and from what used to be called the " horrors of the middle passage ;" so that a slave-ship would arrive at her destination with no contagious fever on board, but saturated : with the filth of her human cargo. The facts discovered by Dr. Audouard in two Spanish outbreaks suggested to him a general theory of yellow fever; it was a peculiar form of typhus due to the emanations from the putrid dysenteric discharges of the negro, and the fever owed its well-marked specific type to the fact that the matters which excited it could be traced to the negro body. There was something, he said, quite peculiar in the negro constitution, and it was not surprising 'that the discharges from his sick body should be able, when fermented, to produce in others a typhus fever of a peculiar type.

Dr. Audouard's papers were communicated to the French Royal Academy of Sciences, and accepted for publication. The Academy, however, did not adopt his opinions, and they pointed out, after the manner of academies, that his facts related to only three slaveships and to only two outbreaks. But the author had shown that a great part of the West Indian trade with Spain was carried on by ships engaged in the contraband slave-trade, and that the same circumstances which led to the epidemics investigated by hirnself must have arisen often at all the Spanish ports where yellow fever was an almost annual occurrence. Not only so, but the whole history and geography of yellow fever in America was on his side; seaports where cargoes of slaves had been landed year after year had presumably become saturated with the peculiar filth of the trade, and it is just the landing-places and shipping-quarters of those ports that are the foci of infection. In some of them, such as Vera Cruz, the poison seems to have become peculiarly fixed in the soil, so as to defy all attempts at getting rid of it. But in the great cities on the Atlantic seaboard of the United States, the fever was practically eradicated soon after the importation of negroes ceased. During the sixteen years after that date (1808), yellow fever appeared only seven times in the different ports of the Union, whereas in the sixteen years preceding the abolition of the traffic it had broken out fifty-eight times.

In the Spanish seaports also, the great epidemics of yellow fever are an almost forgotten tradition. But in Brazil they are of recent date, the first of them as recently as 1849 , and Brazil was then and had been for some time the great market for the African slaves, when the ports of other countries except Cuba were closed to them.

A still more unlooked for confirmation of Dr. Audouard's theory may be discovered in the establishment of yellow fever in the seaports of Peru within quite recent times; the first outbreak having been at Callao and Lima in 1853. An account of it was sent from Lima to the Edinburgh Medical Journal by Dr. Archibald Smith, who says: "The first cases of the Lima fever were vulgarly attributed to the excessively crowded shiploads landed at Callao of poor and sickly Chinese, who were ill-fed, ill-clothed, and badly cared for on the voyage from their native country. But," he adds, "I, as a practitioner, could not trace any symptoms of this fever to them." But Dr. Smith's objection to the popular explanation of the yellow fever in Peru is precisely the strongest argument in favour of it ; the Chinese, like the negroes, did not suffer from yellow fever, and they are said, indeed, never to take it on shore; but they suffered from those dysenteric and other non-contagious ailments. which were the antecedents of yellow fever. The disease, since that time, has appeared at various other ports on the Peruvian coast; its outbreak at one of them, in 1868, was so sudden that the populace attributed it to an earthquake; but a communication sent to the French Foreign Office more reasonably connects it with the Chinese immigration, which; as the report says, has profoundly changed the sanitary condition of the whole Peruvian coast.

But there is another argument for Dr. Audouard's theory, which he makes hardly any use of. It is the immunity of the negro from yellow fever, notwithstanding his great liability to cholera and the common forms of typhus, including ship-typhus. This immunity is perhaps not so striking now, when the negro blood is less pure, but all the earlier authors were much impressed by it. Thus, Doughty, who saw much of yellow fever in Jamaica at the beginning of the century, says: "In the natives of Africa, the constitution appeared to me as secure against yellow fever as a person who has had the small-pox"-and he might have said the yellow fever itself-" is against its recurrence." Fenner, a more recent authority in New Orleans, says : "It is a well-established fact that there is something in the negro constitution that affords him a protection against the worst effects of yellow fever, but what it is I am unable to say." Mr. Clarke, the author of a paper on the "Topography and Diseases of the Gold Coast," in the first volume of the Epidemiological Transactions, says: "I have heard and read of negroes taking yellow fever, but in no 
case did it happen at Sierra Leone during its prevalence in 1837, 1838, 1839,1847 ; nor, so far as I understand, in 1859 ; and no example of it occurred to any of my medical brethren in the course of their practice." This is certainly a remarkable testimony, when we consider that ninety-nine hundredths of the population of Sierra Leone are negroes. And to show that this is the immunity of negro blood, and not of acclimatisation, I take the most remarkable experience of all, that of the French expedition to Mexico from 1862 to 1866. There was a heavy mortality from yellow fever among the motley gathering of troops at Vera Cruz in the summer of.1866; not only the .French soldiers, but Arabs from Algiers, Indians from the interior of Mexico, and Creole troops from the West Indies, were decimated by it; whereas, in a body of 400 negro soldiers from the West Indies, there were only three cases, with one death; and in a black regiment of 500 men raised in the Soudan and Nubia, there was not a single case.

If, then, we put together the facts of this remarkable disease: when we consider that its advent into the world coincided with the rise of the slave-trade; that its habitat is or has been the ports of debarcation of the slave-trade, and those places in Spain and the West Coast of Africa to which slave-ships went on their return voyage that its exacerbations have coincided with the most lawless period of the negro traffic; that it gained a footing in the ports of Brazil in 1849, when the slave-trade flowed into that channel; and that it has become endemic subsequent to 1853 on the Pacific coast of South America, in those ports of Pern which were the seat of an infamous Coolie traffic-we cannot but see in all this concurrence of testimony a proof that Dr. Audouard was right in describing yellow fever as a peculiar form of typhus, originating at all its endemic centres in the filth of slave-ships, just as he showed that it had so originated, as a matter of fact, in two of the Spanish outbreaks. But if that evidence should not be enough, we have only to add the fact that the negro cannot take the disease, although it rages most in the very quarters where negroes live. The yellow fever still lurks about the wharves and shipping quarters of towns where cargoes of slaves used to be landed; and every few years, when the weather is at the hottest, it rises into a pestilence, as if it were the ghost of the slave-trade walking. But it passes by the negro, as if it recognised the ties of blood; and I want no other fact than that to prove that even this infection, belonging to the exogenous group, is but one step removed from perturbations of the normal life, and that it carries with it the indelible stain of its origin.

The connection between yellow fever and the dysenteric and other discharges of the negro body, is only a part of that general connection between dysentery and typhus which has often been noticed in wars and famines. It formed the subject. of a debate, in 1861, before the Epidemiological Society, in which the late Dr. Murchison gave an outline of the argument that he afterwards maintained with so much learning and research in his. treatise on. Continued Fevers. The celebrated cases of jail-fever, in which prisoners brought up at the assizes gave typhus to the judges, and counsel, and jury, are full of pathological interest; and it may be well, at the present day, to recall the fact, which arrested the attention of Lord Bacon, that the prisoners were not suffering from typhus themselves. But we need not go farther back than twenty years ago, or farther away than the city of Liverpool, for proofs of the de novo origin of a specific fever; no more striking proof was ever given of the genesis of typhus out of dysenteric and other filth than in the case of the Egyptian frigate which came from Alexandria to the Mersey in 1862 to be refitted. There were four hundred Arabs on board, who had suffered a good deal from diarrhœea and dysentery; they had met with rough weather all the way from, Alexandria, and the hatches had been battened down for two or three weeks continuously. When the ship arrived in the Mersey, the 'tween decks was in a disgusting state of filth, and the pilot who took the vessel up the river remarked to his wife when he went home that that ship would be heard of again. He was himself the first victim, for he was seized with a fatal form of hæmorrhagic typhus about a week afterwards. More than one hundred of the craw were on the sick-list, chiefly from dysentery, but it was carefully ascertained that none of the cases were typhous. Most of the Arabs went to a public bath in their filthy state, and in a few days typhus broke out among the bath attendants. Some of the crew were admitted into the Southern Hospital for various non-contagious disorders, and there also typhus broke out.

All the facts of this most interesting case were communicated to the Epidemiological Society by the late Dr. Duncan, medical offices of , health.. It was Dr. Duncan's opinion, and also Dr. Cameron's, the present President of the Medical Section, that the outbreak was clearly traceable to the Egyptian ship and her filthy crew, but that it was not traceable to pre-existing cases of typhns, whether on the voyage or in Alexandria before sailing.

There is one other class of cases which I shall just mention-thd cases in which the mere contact of human beings in an average. state of health and cleanliness sets up various epidemic disorcleris among the inhabitants of remote islands, where strangers rarely come. Mr. Darwin, in his narrative of the voyage of the Beagle; quotes instances of this in the South Seas, on the excellent authority of Williams, the missionary; and it is to typhus that. Mr. Darwin compares these cases. "It would almost appear," he safts, "as if the effluvium of one set of men shut up some time together was poisonous when inhaled by others, and possibly more so if the men be of different races."

I shall take one other illustration of the doctrine of acquired autonomy, and I shall take both the faots and the doctrine from Sir Thomas Watson. The. English troops that served in Egypt in 1801, under Sir Ralph Abercromby, suffered much from the ophthalmia of that country, which is always brought on by exposure to cold after being heated, by the glare of the white and parched ground, by the dust in the air, and such-like causes peculiar to the climate of Lower Egypt. No one, in those days, thought that Egyptian ophthalmia was a specific infection. But some of the English soldiers returned with it uncured, and it soon became contagious in the home garri. sons; and it was found, after a lapse of eight or nine years, that there were no fewer than 2,317 soldiers pensioners upon the public bounty from blindness in consequence of ophthalmia. Those whit knew the disease as it occurs in Egypt denied that it was conitagious, and those who saw it in England were as positive that it was contagious. Watson reconciles the two views. He says that "there is nothing absurd nor unlikely in the supposition that dis: eases may first arise from some other source, and then beconie capable of spreading by contagion;" and he says elsewhere: "My own creed upon the matter is this - that the disease may, and often does arise, independently of contagion, from the agency of ordinary causes of inflammation; and that, having so originated, it acquires contagious properties, which develop themselves only under circumstances that favour the propagation of most of the contagious complaints." A parallel to the Egyptian ophthalmia of 1801 may bc found in certain cases of syphilis described by Baron Larrey in his surgical history of the same campaign. The Alexandrian syphilis, which the French troops contracted freely, was peculiarly free from "grave symptoms" and "easily cured"; but it proved very "btostinate and difficult to destroy" in those who brought it back with them to Francé.

In choosing to speak of infective diseases from a standpoint which is not the dominant standpoint of the time, I fear that I have laid myself open to the chatre of taking advantage of a public opportunity in order to get a hearing for. a somewhat peculiar view; but the words which I have just quoted from Sir Thomas Watson will show that this doctrine of common disorders acquiring specific power has not been absent from the thoughts of those who lived in the phiro. sophical period of medicine. Nothing would be more agreeable than to adduce other instances of the same kind from the history of medicine, and I especially regret that time will not permit me to say something of this principle of autonomy, as it was held by the thoughtful and talented writers who were known in Germany fifty years ago as the natural-history. school. But in anything that concerns the natural history of disease, we may go direct to Sydenlvalin, who was the author of the phrase, and in Sydenham we shall. find $\mathrm{d}$ viery explicit statement of the doctrine of an acquired autonomy, jancl a preautonomous stage in the specific diseases. Sydenham uses the language of the humoral pathology of his time, but that mattors little. The humours, he says, may, under certain circumstancess, be raised to the dignity of a substantial form or to a species, a spegific disease being:one that takes its rise in this specific exaltation $n_{j}$ gr specification of some.juice of the body; and he expressly mentions the antecedent condition of the humour before it had pat on its spieies-axtequam hanc induerat speciem. If I have proferrect, to speak of the aoquired autonomy of a disease, and of its preatitiph mous stage, I mean no more than Sydenham means here, as, the context of the paissage wauld show.

Sydenham compares these species of disease to the species of animials and plants; only that their life is an integral part of the general life of the body; and as we have an Origin of Species for anitals and plants, it is natural to think of the origin of diseasp species. . But there is a difficulty in the latter which the Darwinian problem is free from. . In the origin of species, we are dealing with indixidual things; each with its well rounded, independent; life 
but where is the individual life in disease? In my humble opinion, the germ will not serve our purpose, for, according to the great Darwinian analogy, the germ is always a part of the individual, and always presupposes the individual. The germ, or the sperm, is no donbt a peculiarly important part, and it is charged with the most marvellous representative powers; but it is always representative of the individual, and it derives its powers from the individual. Such, at least, is our only analogy.

If, then, we must have the individual to start with, before we can apply the "origin of species" to disease, we come back to the old question, how a morbid state of the body can become a semi-independent thing, how it can exist, not in absolute independence of the body, but autonomous within it, an imperium in imperio. This is the perplexing question which I stated at the outset with reference to cancer, a disease which, in the popular estimation is almost synonymous with a semi-independent life, and I quoted the words of Paracelsus: "In such a disease, a man is himself and another; he has two bodies at one time, enclosed the one in the other, and yet he is one man." I have spoken to several metaphysical friends of the difficulty of conceiving how a mere state of the body, a complex or integrated morbid state, can become an individual existence with the power of propagating itself; but I cannot say that I have got any. thing satisfactory out of them. We shall probably have to settle this question within our own science as a part of the subject-matter of pathology. Pathology is indeed varied enough in its subjectmatter. It studies disease on many sides, as the founder of this Association planned that it should be studied-the side of its anatomy and its physiology, of its geography and its ethnology, of its history and its natural history. Its aspects are as various and attractive as the fruit trees in the Mohammedan paradise. But there is nothing in all this boundless field of inquiry that is more likely to occupy the mind of the profession for years to come, as it has occupied it in times"past, than the difficulty for conceiving how a state or condition of the body can become a species of disease.

\section{A N ADDRESS}

DETIVERED AT THE OPEXTEG OF

\section{THE SECTION OF OBSTETRIC MEDICINE, \\ At the Annual Meeting of the British Medical Association in Liverpool, August, 1883.}

BY GRAILY HEWITT, M.D., F.R.C.P.,

Professor of Obstetric Medicine, University. College; President of the Bection.

\section{THE QUESTION OF FOOD IN OBSTETRIC AND} GYNACOLOGICAL PRACTICE.

Gentlemen, - Permit me, in the first place, to express the deep sense which I entertain of the honour conferred upon me by the Council of the Association in requesting me to preside over the meetings of this section. I trust that I shall be favoured with your kind indulgence in endesvouring, to the best of $\mathrm{my}$ ability, to fulfil the duties entrusted to me.

It is with much pleasure that I congratulate the section, and our esteemed colleague, Sir Spencer Wells, on the public recognition of his important services in the cause of humanity which is embodied in the honour which he has recently received. The extended application of surgical skill to the relief of a class of diseases which were formerly considered incurable, and in which Sir Spencer Wells has taken so considerable a part, constitutes a great claim by gynmoological practitioners on the gratitude of the public, and I am quite sure that you will join with me in felicitating our distinguished colleague on his well-merited reward. None the less is the profession to be congratulated on the further recent developments in the application of surgical skill to the relief of suffering which have been made by gynæoologists, as evidenced by the fact that novel and bold operations, which were hardly thought of as possible before ovariotomy had become an established suocess, have of late been performed with a large amount of success also.

While, however, we congratulate ourselves on the brilliant achievements of gynæcological surgery, it is well to be reminded that there are other kinds of work to be done, on the due carrying out of which the lives and health of vast numbers of the community depend, and in which, as gynzcologists, we are deeply interested.

I take advantage of this opportunity to present to you a few ob- servations on a matter which has for some years deeply interested me, and concerning which I have arrived at conclusions which, to me at all events, appear to possess a certain value, viz., The Question of Food in Obstetric and Gynæcological Practice.

Now, it may appear unnecessary at this period of medical history, and in the present advanced state, as it is considered to be, of medical knowledge, to insist on the importance of food in maintrining a healthy activity of the vital processes. But a lengthened experience has convinced me that the public at large have no practical knowledge of this, and that the most disastrous effects result in multitudes of cases from this ignorance of simple physiological laws.

Engaged as $I$ have been more particularly in obstetric and gynæcological practice, the non-observance of these important physiological laws in connection with the occurrence of diseases of the uterus, disturbances of the functions of the uterus and ovaries, and the diseases incidental to child-bed, has forced itself on my notice. It is pretty certain that the generalisation which applies to these classes of disease extends, or would be found to extend, to diseases of other organs of the body, for it is the merit of a true generalisation that it is of wide application.

There are certain terms in general use by the public and by the profession which are often employed in a vague, unmeaning, and indefinite manner-such as "weakness," "delicacy," etc.-whereby it is intended to designate a condition very frequently met with, but the essential nature of which is, as my experience has shown me, very imperfectly apprehended. It is well recognised that this weakness, delicacy, or what not, is very commonly observed not only in young women coming under the notice of the gynæcologist, but also in women who have arrived at adult age, and suffering from disorders in connection with pregnancy, parturition, and childbed. My observation has in a particular degree been attracted to the presence of this condition. I have taken every opportunity in my power for analysing its nature and ascertaining its essential cause. One conclusion arrived at is, that this general weakness is very far more common than is supposed as an antecedent in cases coming under our notice as gynæcologists, and it may even be said that it is almost invariably present in a marked form in such cases. Another conclusion is, that the "weakness" is associated with and caused by a long-continued inadequate dietary, and that it is essentially what may be termed "chronic starvation." The rational view of the matter is, that this "weakness" is, in the very large majority of cases, preventable; that it should be regarded as the first stage of a serious possible disease; that it is mostly the result of chronic starvation ; that it is curable, to a greater or less degree, in most cases; and that it is of the highest importance that it should be formally and carefully treated, as other diseases are, instead of being allowed to smoulder on until the constitution is thoroughly undermined, or until some ailment distinctly classified in our nosology makes its appearance.

It may be asserted that, as yet, neither the public nor the professional mind has seized the importance of preventive measures in regard to disease. It is, indeed, true that the sanitary engineer is at work in our houses; but it cannot be said, as yet, that anything like systematic attention is devoted to the maintenance of healthy and vigorous growth, and the prevention of those diseases which are ultimately so deadly in their effects in many cases; I mean what may be termed the nutritional diseases incident to the human frame.

The analogy between the growth of a plant and of the human organism is one which has been often pointed out. The various chemical changes involved in a continuance of healthy growth in the plant and in the animal, are well capable of definition. We know that the plant requires air, moisture, and a supply of nutritive material regularly, and in sufficient quantity. And we should know, for physiologists inform us of the fact, that the vital processes in the human organism require, for their continuance in a vigorous state, material supplies of a suitable kind, as well as hygienic surroundings, fresh air, and the like. Again, it is well known by good gardeners that nothing so effectually protects the plant from external injurious influences, from blight, from the attacks of parasites, from insects, and from the diseases to which plants are liable, as the maintenance of the plant in a state of active growth. Once let the growth fall off in its vigour, the plant becomes forthwith liable to fall a victim to canker, to the pestiferous invasion of insects, to deterioration, to weakness, and often to decline and death.

It is a remarkable circumstance that so little as yet seems to have been done in the investigation of the effects of an insufficient dietary, looking at it from the quantitative point of view, although the effects of complete deprivation of food are well known. Thus, in the last edition of Parkes' well known work on hygiene, it is stated 